\title{
Design methodology for low cost tubular digesters
}

\author{
J. Martí-Herrero*, J. Cipriano \\ Centre Internacional de Mètodes Numèrics en Enginyeria (CIMNE), ${ }^{1}$ Building Energy and Environment Group, C/Dr. Ullés, 2, 3r, 08224, Terrassa, Barcelona, Spain
}

\section{A R T I C L E I N F O}

\section{Article history:}

Received 27 October 2011

Received in revised form 16 December 2011

Accepted 17 December 2011

Available online 5 January 2012

\section{Keywords:}

Low cost tubular digester

Anaerobic digestion

Design methodology

Dimension

Trench

\begin{abstract}
A B S T R A C T
The aim of this paper is to present a novel, universal, methodology for the design of low cost tubular digesters. This method improves on the established methodology by avoiding assumptions that tend to reduce the final hydraulic retention time (HRT) of digesters once installed. This work recommends designing the digester using trench cross-sectional area and proposes an optimization of the trench dimensions with respect to the angle of the walls and the relationship between the length of the biogas bell and the top width of the trench. The influence of the biogas pressure is considered. A simple geometrical analysis is presented that, by parameterization, can be applied in a wide range of situations.
\end{abstract}

(c) 2011 Elsevier Ltd. All rights reserved.

\section{Introduction}

Low cost digesters have been implemented in developing countries such as Colombia, Ethiopia, Tanzania, Vietnam, Cambodia, China, Costa Rica, Bolivia, Peru, Ecuador, Argentina, Chile, Mexico, etc. since 1980s (Botero and Preston, 1987; Soeurn, 1994; Solarte, 1995; Sarwatt et al., 1995; Rodriguez and Preston, 1999; Martí-Herrero, 2007; Poggio et al., 2009).

Low cost digesters are characterized by the absence of both active mixing devices and active heating systems and also, consequently, by not needing sophisticated monitoring. Local materials are used for construction, usually plastic bags for the main tank and PVC pipes to carry the biogas. This technology works, with proper adaption, in tropical, continental, and cold climates, usually feed by fresh manure from dairy or pigs (Martí-Herrero, 2007; Martí-Herrero, 2008; Poggio et al., 2009; Ferrer et al., 2011). Due to their simple design and construction from readily-available materials, they are considered appropriate technology.

The "red mud PVC" bag designed in Taiwan (Pound et al., 1981) was the seed for the technical development of this continuous-flow flexible tube. Further development was conducted mainly by Preston in Ethiopia, Botero in Colombia (Botero and Preston, 1987) and Bui Xuan An in Vietnam (Bui et al., 1995). In all cases the digesters were adapted for tropical climates. Martí-Herrero (2007, 2008), in the Altiplano of Bolivia in 2003, adapted Botero's design to cold climates increasing the hydraulic retention time (HRT) to 90 days and

\footnotetext{
* Corresponding author.

E-mail address: jaimemarti@cimne.upc.edu (J. Martí-Herrero).

1 http://www.cimne.upc.edu.
}

adding a greenhouse with high thermal mass adobe walls and straw as insulation in the trench. Poggio et al. (2009), in Perú, proposed adding to the Martí-Herrero model a simple solar heating system, integrated in the design by taking advantage of the structure of the cold climate digester.

There have been scientific publications regarding tubular, non low-cost, digesters dealing with the co-digestion of vegetable wastes by Dinsdale et al. (2000), and on the subject of fruit and vegetable waste treatment by Bouallagui et al. (2003), co-digestion of olive mill wastewater with olive mill solid wastes by Boubaker and Ridha (2007), and operation of a laboratory-scale tubular digester on piggery waste by Floyd and Hawkes (1986).

A few scientific publications in indexed journals exist about low cost tubular digesters which offer analyses of efficiencies and applications. Ong et al. (2000) reports a study to evaluate which layer inside a single-stage digester should be evacuated as effluent in order to improve biogas production, concluding that it was the middle one. Lansing et al. (2008a) published a study about seven low cost digesters in Costa Rica to determine the potential of these systems for treating animal wastewater and producing renewable energy yielding a positive conclusion. In the same year Lansing et al. (2008b) published research on electricity generation from a low cost biodigester as a waste treatment solution for a pig and cow farm, finding that the economic investment could be recovered in 7.6-10.1 years depending on the generator used. Ferrer et al. (2009) reports a study of the viability of ambient temperature anaerobic digestion of pig manure diluted with urine and obtains good results. Lansing et al. (2010a) reported a study in which a small amount of waste cooking grease (2.5\% by volume), when added to swine manure more than doubles $\mathrm{CH}_{4}$ production, 
demonstrating a good opportunity for these digesters to improve their performance while preserving the waste treatment value of the low-cost digestion system (Lansing et al., 2010b).

Ferrer et al. (2011) has recently published the results of two monitored tubular low cost digesters in the Peruvian Andes, obtaining a biogas production rate of around $0.35 \mathrm{~m}^{3} \mathrm{~kg}_{\mathrm{vs}}{ }^{-1}$, for HRTs of 60 and 90 days, with an organic load rate (OLR) below $0.75 \mathrm{~kg}_{\mathrm{vs}} \mathrm{m}^{-3} \mathrm{day}^{-1}$. Ferrer proposes to investigate HRT below 60 days and OLR above $1 \mathrm{~kg}_{\mathrm{vs} \mathrm{m}} \mathrm{m}^{-3} \mathrm{day}^{-1}$ in order to "decrease digesters' volume (i.e. costs) and increase biogas production rate" to fulfill the biogas requirements of a family for cooking and lighting. In this sense, Martí-Herrero (2011) communicated that "one of the problems reported from field surveys of this type of digester is that end-users complain that daily biogas yields are less than those indicated by the designers" and observed that two common errors in the design of low cost tubular digesters, also the Peruvian Andes ones, that decrease the real HRT. This observation helps to explain the low biogas production identified by Ferrer and Marti-Herrero.

Alvarez et al. (2006) reported the results of the evaluation of the effects of pressure (495 and $760 \mathrm{~mm} \mathrm{Hg}$ ), temperature (11 and $35^{\circ} \mathrm{C}$ ), HRT (20 and 50 days), and manure content in the slurry $(10 \%, 20 \%$ and $50 \%)$ respect to productivity and methane yields from cow and llama manure digestion. This conditions are referred to high altitude cold climate conditions as Peruvian Andes or the Bolivian Altiplano. Alvarez determined that the effect of the pressure is not significant while the main factor to achieve a better productivity and methane yield is the temperature. The temperature
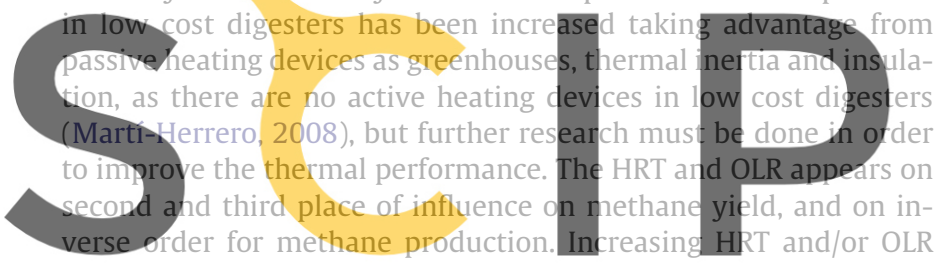

will result in higher productivity and methane yields. The OLR is more related to the operational phase, to the content of VS on

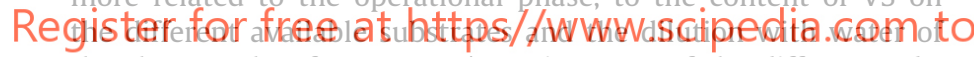
the slurry. Other factors as C/N ratio or PH of the different substrates can also affect the productivity and methane yields of the digester. These both factors use to be corrected by the digester user adding paper or rice shells to increase $\mathrm{C} / \mathrm{N}$ ratio on pig and human manure, or adding calcium carbonate (agricultural lime) to reach a proper $\mathrm{PH}$ when it is low. So OLR, C/N or PH are parameters to be considered but dependent to the type of substrate to be used and the operational phase. The HRT is directly dependent to the temperature and design phase, and in order to standardize and industrialize low cost digesters become a critical factor to be considered.

The aim of this paper is to develop a new, universal, methodology for the design of low cost tubular digester. The old common design methodology, employed by all the authors (Botero and Preston, 1987; Bui et al., 1995; Sarwatt et al., 1995; Rodriguez and Preston, 1999; Aguilar, 2001; Martí-Herrero, 2008; Poggio et al., 2009), assumes that the final liquid volume is determined by the cylinder shape of the tubular plastic whilst, in reality, the critical factor is the trench dimensions, as reported by MartíHerrero (2011). This erroneous assumption results in a reduction of the HRT once the digester is placed in the trench. How to determinate the cost-effective dimensions of the trench and to keep the HRT once the low cost tubular digester is installed and working affected by the biogas pressure?

In this paper, a geometrical analysis of the low cost tubular digester is realized, and a general methodology to determine the optimum dimension for the trench is proposed. The advantage over the old method is that the designed HRT is achieved once the diges- ter is installed. The gap filled in the body of knowledge is the explanation of why actual HRT has tended to be lower than expected.

\section{Old common design methodology}

As there is no information in peer-reviewed journals about the design and dimensioning of low cost digesters, the primary source of information on the subject is the Internet. Low-cost tubular digesters are generally made of sheet plastic (low-density polyethylene (LDPE), high-density polyethylene (HDPE) or polyvinyl chloride (PVC)), and hence they are flexible and take the form of the container in which they are installed; most commonly in a trench in the ground. On the Internet (Botero and Preston, 1987; Bui et al. 1995; Sarwatt et al., 1995; Rodriguez and Preston, 1999; Aguilar, 2001; Martí-Herrero, 2008; Poggio et al., 2009), specific trench dimensions can be found for various circumferences of plastics used.

The methodologies reported for the design a low-cost tubular digester use the cylindrical volume that the tubular plastic forms as the central parameter. This total volume is separated into two phases-liquid and gas. Depending on the author, the liquid volume is reported as $80 \%$ of total cylindrical volume (Bui et al., 1995; Sarwatt et al., 1995; Rodriguez and Preston, 1999; Poggio et al., 2009) or 75\% (Botero and Preston, 1987; Aguilar, 2001; Martí-Herrero, 2008). The liquid volume is supposed to fill the volume of the trench in which the digester is situated. In order to obtain the total volume, the cross section of the cylinder is multiplied by the length of the digester, assuming that this volume will re-
main unchanged after the digester is placed in the trench. The
dimensions of the trench are given in each case as 'recommended',
but no methodoldgy or justification is provided. Hoyever, these
dimensions are critical because, in practice, they determinate the
real liquid volume.
IViarti-Herrero (2011) reported that the recompended dimen-
sions, in most cases studied, are not consistent with the circumference of the plastic. Also, in the cases where the data is coherent, the

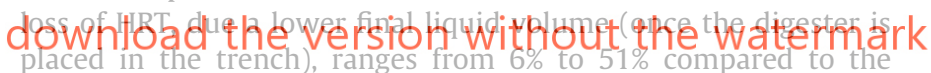

HRT expected by the design. In the same report Martí-Herrero highlighted that the biogas pressure influences the final HRT and can result in a reduction of between $15 \%$ and $17 \%$ compared to the theoretical value expected by design.

The complaints about lower daily biogas production rates than those indicated by the designer, can be related to the issues reported by Martí-Herrero (2011) about design considerations and the high HRT and low OLR identify by Ferrer et al. (2009). These complaints can also be related to other factors associated to user behavior that also adversely affect production rates, such as not loading the digester with fresh manure every day or loading less manure than recommended. Other factors as the quality of the substrate used are hardly modified, and $\mathrm{C} / \mathrm{N}$ ratio or $\mathrm{PH}$ can be corrected by user as commented before.

\section{Sizing tubular low cost digesters}

\subsection{Available circumference}

The low-cost tubular digester is limited by the dimensions of the LDPE, HDPE and PVC plastics available in the local market. Generally LDPE plastic is manufactured in tubular form with circumferences of 2, 4, 5, or $8 \mathrm{~m}$. HDPE plastics, in the Bolivian market, can be found in flat sheets $7 \mathrm{~m}$ in width, and the PVC ones are often $1.4 \mathrm{~m}$ wide, so the possible circumferences must be a multiple of these measurements assuming they are joined edgewise to form a tube. 
The available circumference must be distributed, in the optimum fashion, between the perimeters of the trench $(a+2 A)$ which determines the liquid volume, and the biogas bell length $\left(L_{b e l l}\right)$ which determines the biogas volume (see Fig. 1).

\subsection{Shape of the trench}

The trench of a tubular digester determines its liquid volume. The ideal optimum cross-sectional shape of the trench would be circular, keeping the original form of the plastic and taking advantage of the full available capacity. But, due to the fact that a circular shaped trench is challenging to dig, in rural areas the trend is to dig polygonal shapes. The more sides a polygon has, the closer it approximates a circular shape and cross sectional area. But an octagonal or hexagonal shape is just as challenging to build in rural areas as a circular shape. Thus trapezoidal shapes are typically dug, as they are the easiest and most common shape and also as this is the shape proposed by all the authors.

\subsection{Volume of a tubular digester situated in a trapezoidal trench}

The total volume $V_{B D G}$ is given by the cross section of the circular segment, $C S_{\text {bell, }}$ plus the trapezoidal cross section, $C S_{\text {trench }}$, multiplied by the length of the digester, $L$.

$V_{\text {BDG }}=\left(C S_{\text {bell }}+C S_{\text {trench }}\right) \cdot L$

where $C S_{\text {bell }}$ is:

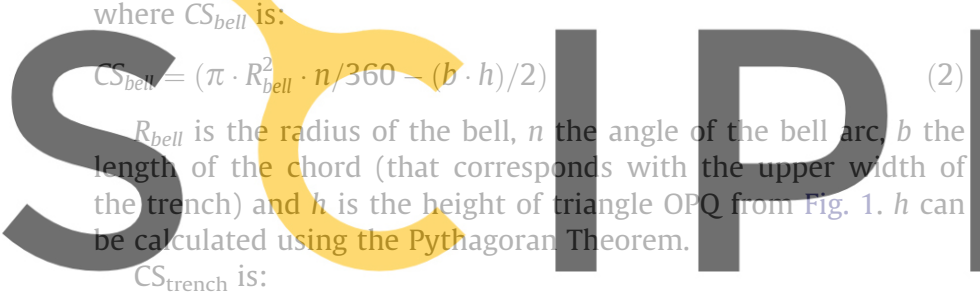

\section{$C_{\text {trench }}=p(b+a) / 2$
Register for free at https//www.scipedia.com to
where $p$ is the depth and $a$ is the lower width of the trench.}

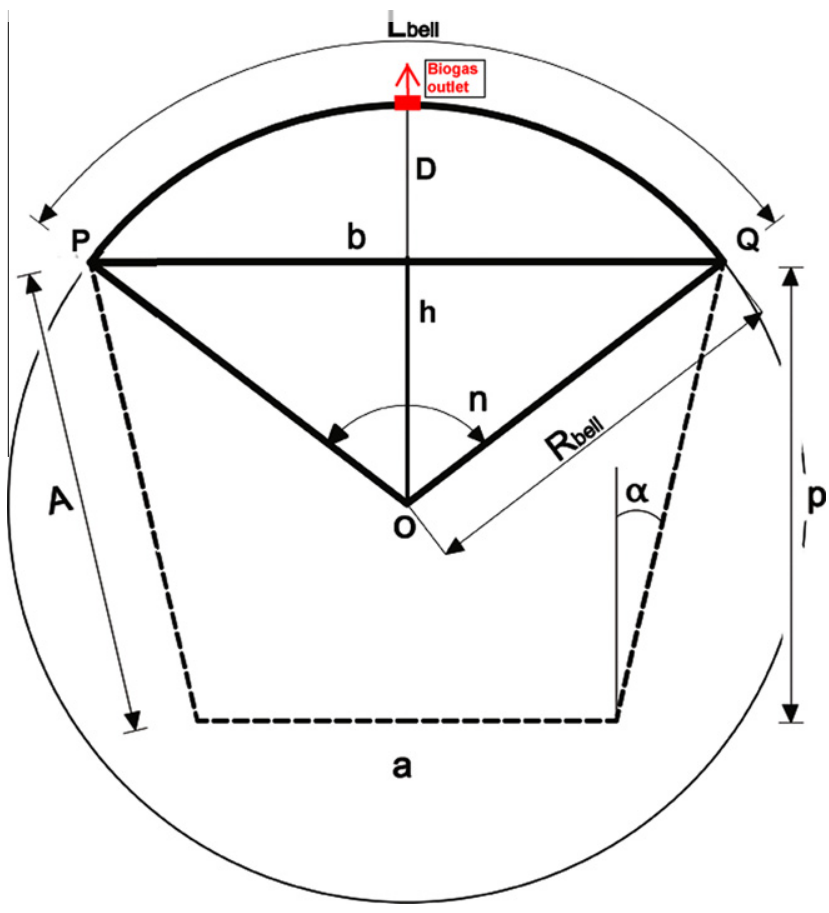

Fig. 1. Geometrical parameters for the tubular low cost digester installed in a trench.

\section{Parametric dimensions of a tubular low cost digester}

In order to generate universal methodology, independent of the circumference of plastic available, $C$, a parametric study is proposed. All values are divided by the radius $r$ of the plastic tube.

$c=2 \pi r$

So the factors are:

$f_{b}=b / r$

$f_{a}=a / r$

$f_{p}=p / r$

\subsection{Dimensions for the biogas bell}

The dimension of the biogas bell determines the capacity of the digester to store biogas. In some cases larger biogas bells will be desired. In other cases external biogas reservoirs will be used, and the biogas bell can be kept smaller. In all cases it is important to maintain a minimum biogas bell size in order to avoid possible blockage of the biogas flow out of the tube in the upper part of the bell which can be caused by two main factors: (a) the formation of foam obstructing the biogas outlet and (b) obstruction of the biogas outlet by suspended solids in the surface of the liquid phase, in situations where the biogas pressure is low.

The length of the bell arc, $L_{\text {bell }}$, has the mathematical expression:

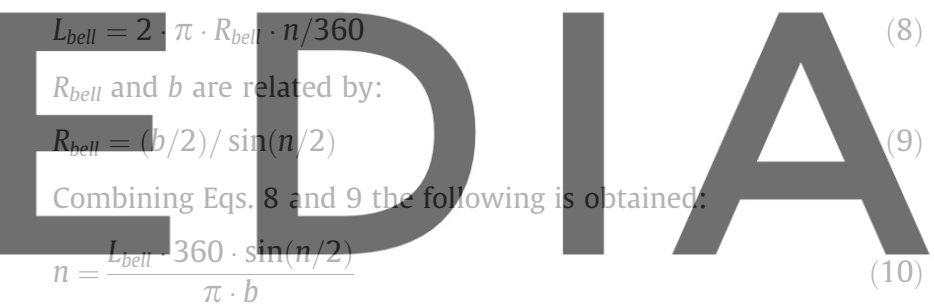

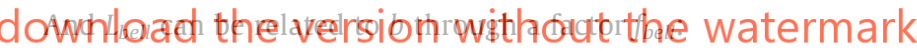
$f_{\text {bell }}=L_{\text {bell }} / b$

So, it is found that the angie $n$ of the beil arc is a function of $f_{\text {bell }}$, as shown in Eq. 12.

$n=\left(f_{\text {bell }} \cdot 360 / \pi\right) \sin (n / 2)$

Using an iteration of Eq. 12, the angle $n$ can be obtained for each $f_{\text {bell }}$, being $f_{\text {bell }}$ the determining factor which characterizes the biogas bell. In Table 1 some results are shown. The curve plotted with these results can be fitted to a 6th-degree polynomial equation, with $R^{2}=1$ and valid for the range $1<f_{\text {bell }}<3$, as follows:

$$
\begin{aligned}
n= & -25,085 f_{\text {bell }}^{6}+333,74 f_{\text {bell }}^{5}-1835,2 f_{\text {bell }}^{4}+5352,7 f_{\text {bell }}^{3} \\
& -8787,9 f_{\text {bell }}^{2}+7829,3 f_{\text {bell }}
\end{aligned}
$$

The cross section of the biogas can be related to the tubular one, using $R_{\text {bell }}$ from Eq. 8 and Pythagoras theorem for $h$ (see Fig. 1):

$\frac{C S_{\text {bell }}}{C S_{\text {tubular }}}=\left(f_{b}^{2} / 4 \pi\right) \cdot\left(360 f_{\text {bell }}^{2} / \pi n-\sqrt{\left(360 f_{\text {bell }} / \pi n\right)^{2}-1}\right)$

So, if $f_{\text {bell }}$ is determined, $n$ can be estimated by Eq. 13. $f_{b}$ will be explained below and will be a function of $f_{\text {bell }}$ and $\alpha$. So $C S_{\text {bell }} / \mathrm{CS}_{\text {tubular }}$ is function of $\left(f_{\text {bell }}, \alpha\right)$.

Table 1

Different values of $f_{\text {bell }}$ and its corresponding angle $n$.

\begin{tabular}{llllllll}
\hline$f_{\text {bell }}\left(L_{\text {bell }} / b\right)$ & 1.1 & 1.2 & 1.3 & 1.5 & 1.75 & 2 & 2.5 \\
\hline Angle $n\left({ }^{\circ}\right)$ & \multirow{2}{*}{86} & 118 & 140 & 171 & 198 & 217 & 244 \\
\hline
\end{tabular}




\subsection{Dimensions of the trench}

The dimensions of the trench are determined by the angles of the walls $\alpha$, and the desired capacity of the biogas bell, related to $f_{\text {bell. }}$, once $\alpha$ is determinate.

A trapezoidal shape is used commonly in civil engineering when designing retaining walls. The desired angle $\alpha$ is not universal and, depending the type of soil, a different angle $\alpha$ could be required. So $\alpha$ is considered a determinant parameter for the sizing of the digester.

In this case, the trigonometric relationship is fulfilled:

$\sin \alpha=[(b-a) / 2] / A$

where $A$ is the apothem.

The circumference of the available plastic is distributed as follows:

$C=2 \cdot A+a+L_{\text {bell }}$

Combining Eqs. 15 and 16 a can be isolated, and dividing by $r$ the next expression is obtained:

$f_{a}=\left[f_{b}-\left(2 \pi-f_{b} \cdot f_{b e l l}\right) \sin x\right] /(1-\sin x)$

The depth of the trench, $p$, can be expressed by $f_{p}$ as:

$f_{p}=\left(f_{b}+f_{a}\right) /(2 \cdot \tan \alpha)$

And defining the factor $f_{A}=A / r$, this gives:

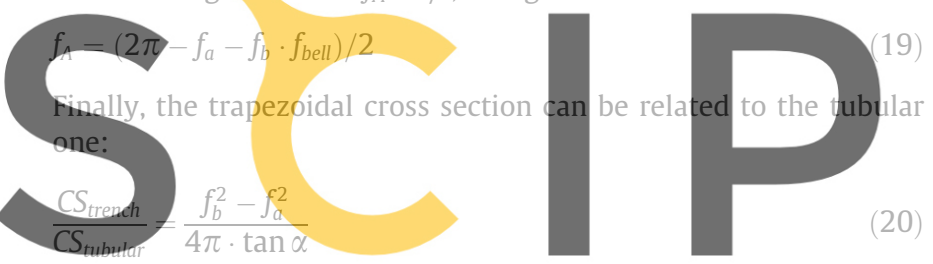

where $f_{a}$ is a function of $\left(f_{\text {bell }}, f_{b}, \alpha\right)$ as shown in Eq. 17. So CS trench/

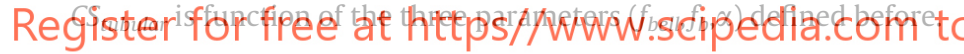

\section{Optimization of the dimensions of the trench}

The optimum trench is the one with the largest trapezoidal cross section area $C S_{\text {trench }}$, constrained by the circumference of the plastic available $C$, and defined by the angle $\alpha$ of the walls and the ratio $f_{\text {bell }}$.

Using Eq. 20 for each $\left(f_{\text {bell }}, \alpha\right)$ the optimum $f_{b}$ value can be calculated, that is the one which will generate the highest $C S_{\text {trench }} / C S_{\text {tubular }}$.
In Fig. 2, the variation of the ratio $C S_{\text {trench }} / C S_{\text {tubular }}$ is plotted with $f_{b}$, for different angles $\alpha$ in the case of $f_{\text {bell }}=1.3$. In this way, the optimum $f_{b}$ can be determined for each $\left(\alpha, f_{\text {bell }}\right)$.

Knowing the optimum $f_{b}\left(\alpha, f_{\text {bell }}\right)$, the rest of factors $f_{a}, f_{p}$ and $f_{A}$ can be determined. Finally, by assigning a circumference $C, r$ can be obtained and the dimensions $a, b, p, A$, and $L_{b e l l}$ can be calculated for the specific case.

\section{Results and discussion}

The optimum $f_{b}$ for different $\left(\alpha, f_{\text {bell }}\right)$ is shown in Table 2 , which includes the corresponding optimum $f_{a}$ and $f_{p}$. The case where $f_{\text {bell }}=1$ corresponds with the reference case of a digester without biogas bell, having total volume equal to the liquid volume contained in the trench.

In Fig. 3 the variation of $C S_{\text {trench }} / C S_{\text {tubular }}, C S_{\text {bell }} / C S_{\text {tubular }}$ and $C S_{B D G} /$ $C S_{\text {tubular }}$ are plotted with the angle $\alpha$ of the walls, for the specific case of $f_{\text {bell }}=1.2$. This behavior is similar for other values of $f_{\text {bell }}$. It is found that $C S_{\text {trench }} / C S_{\text {tubular }}$ decreases and $C S_{\text {bell }} / C S_{\text {tubular }}$ increases with the angle $\alpha$ of the walls.

Fig. 4 shows the variation of $C S_{\text {trench }} / C S_{\text {tubular }}, C S_{\text {bell }} / C S_{\text {tubular }}$ and $C S_{B D G} / C S_{\text {tubular }}$ with $f_{\text {bell, }}$, for the specific case $\alpha=7.5^{\circ}$. The behavior here is similar for other values of $\alpha$. The relationship $C S_{\text {bell }} / C S_{\text {tubular }}$ decreases smoothly and $C S_{\text {bell }} / C S_{\text {tubular }}$ keep more or less constant for values $f_{\text {bell }}>1.3$.

From Figs. 3 and 4, can be shown that, on the best cases of opti-

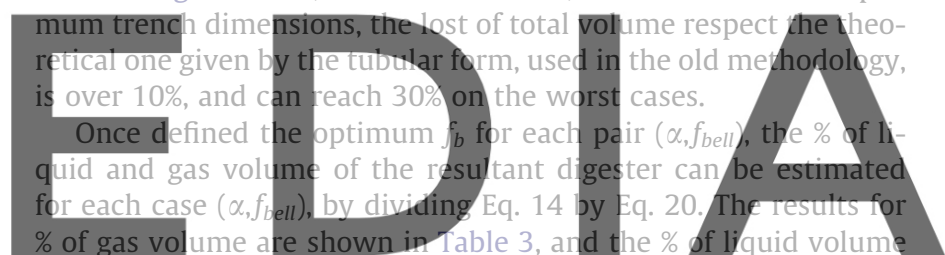

can be derived.

The authors considered proposed $75-80 \%$ of liquid volume with

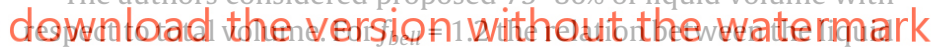
and total volume is $80 \%$, as can be found in Table 3. In this case, the distance $D$ (see Fig. 1) between the top of the biogas bell (corresponding with the biogas outlet) and the liquid level is 0.46 times the radius $r$, enough to avoid the obstruction of the biogas outlet.

The mean angle $\alpha$ used by the considered authors is $7.6^{\circ}$.

So, if $f_{\text {bell }}=1.2$ and $\alpha=7.5^{\circ}$ are selected, the optimum factors are obtained by Table 2, and a resume is showed in Table 4 .

Using these factors for the typical circumferences of plastic used, and adding circumferences for HDPE (7 and $14 \mathrm{~m}$ ) and PVC

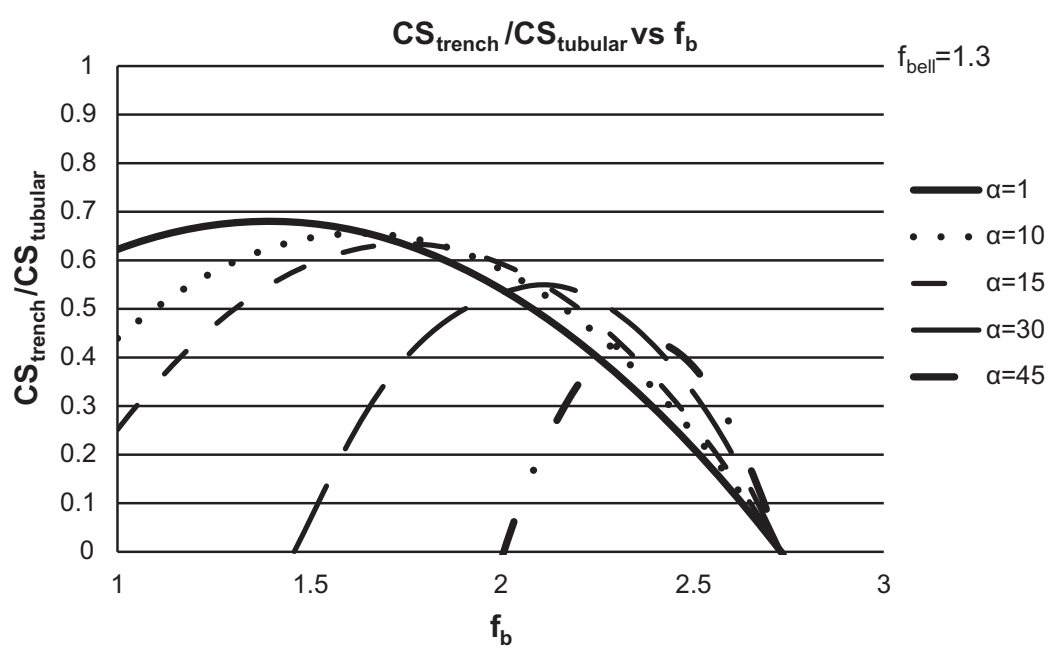

Fig. 2. $C S_{\text {trench }} / C S_{\text {tubular }}$ relation variation with $f_{b}$, for different angles $\alpha$ in the case of $f_{\text {bell }}=1.3$. 
Table 2

Optimum factors $f_{a}, f_{b}$ and $f_{p}$, for different $\left(\alpha, f_{\text {bell }}\right)$.

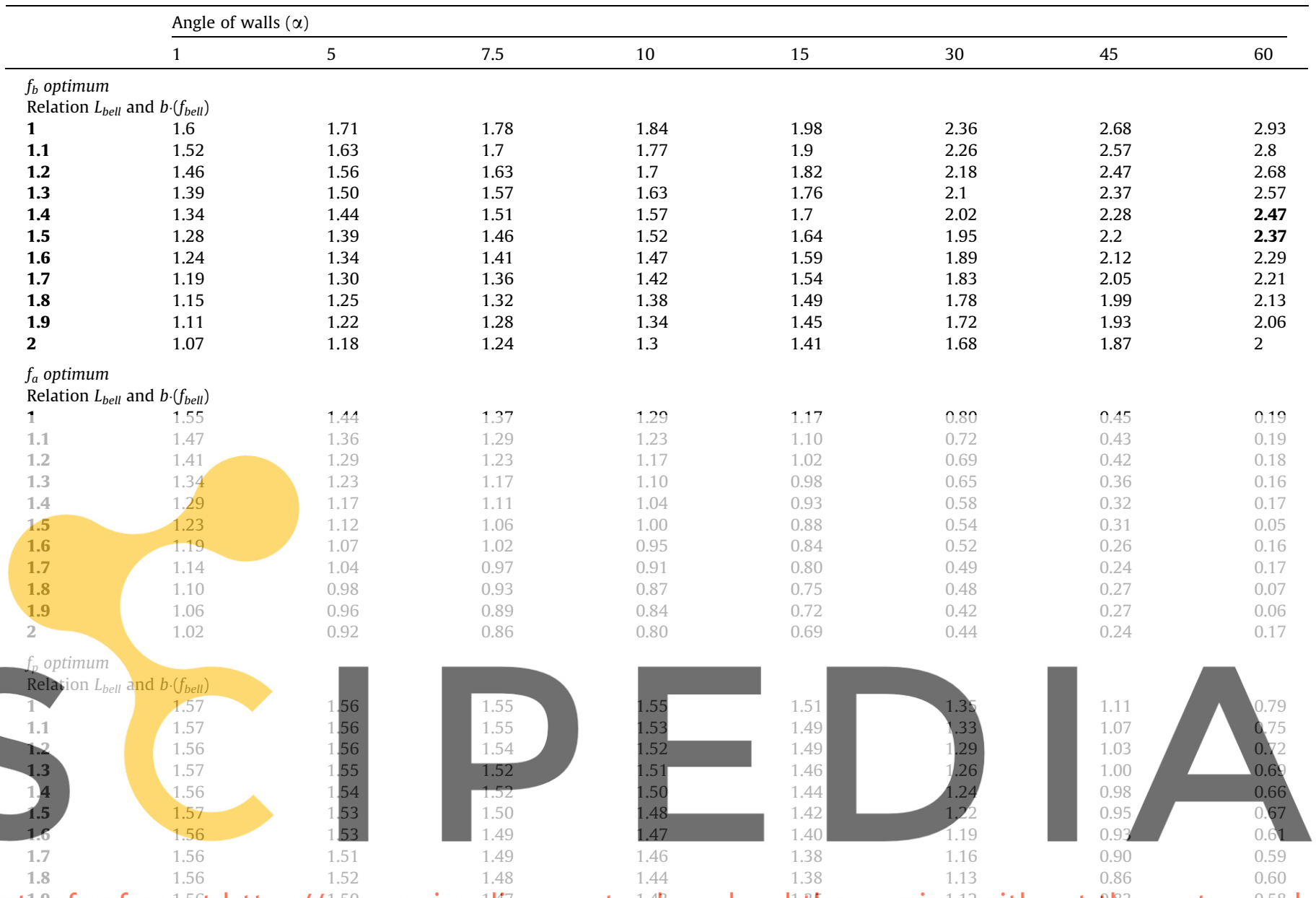

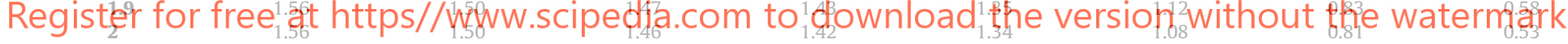

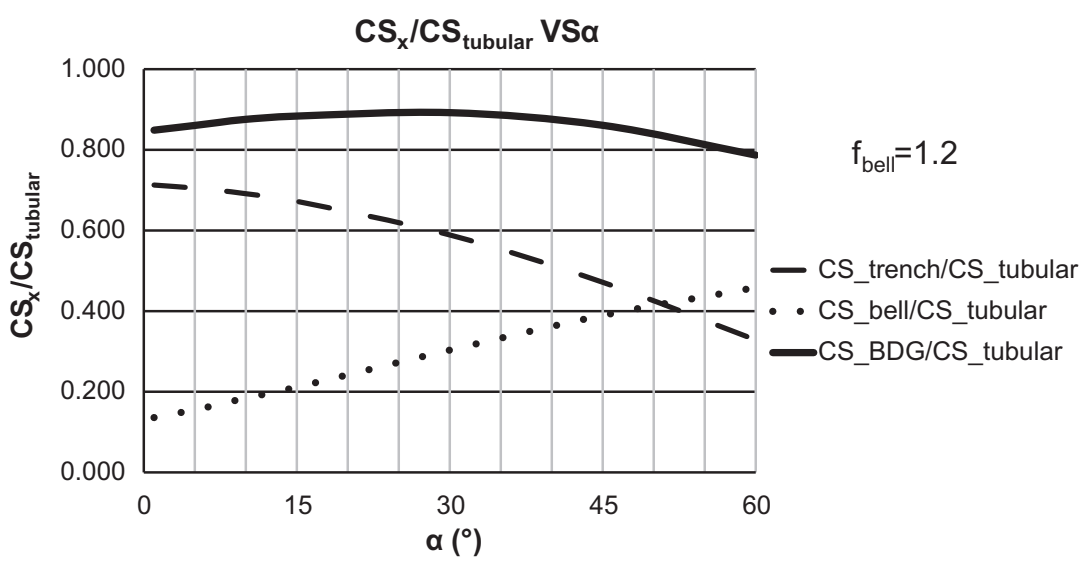

Fig. 3. Variation of $C S_{\text {trench }} / C S_{\text {tubular }}, C S_{\text {bell }} / C S_{\text {tubular }}$ and $C S_{B D G} / C S_{\text {tubular }}$ with $\alpha$ for a fixed $f_{\text {bell }}=1.2$.

(multiples of $1.4 \mathrm{~m}$ ), the optimum dimensions for the trenches are found, as shown in Table 5.

\section{Final considerations for biogas pressure influence on HRT}

The liquid volume and so the HRT calculated with this methodology is for biogas pressure equal to atmospheric pressure. As the pressure inside the digester increases, the volume of biogas increases and the level of the liquid inside the digester decreases, resulting in a reduced volume of volume (Martí-Herrero, 2011).

To estimate this loss of liquid volume, it is necessary to calculate the new $p$ and $b$, due the drop in liquid level, while $a$ keeps invariable. $h_{p}$ is the mean pressure inside the digester expressed in meters of water column. The new depth is $p^{\prime}=p-h_{p}$, and $b^{\prime}=b-2 \cdot h_{p} \cdot \tan \alpha$. Introducing $a, b^{\prime}$ and $p^{\prime}$ in Eq. 3 the new final $C S_{\text {trench }}^{\prime}$ is obtained. 


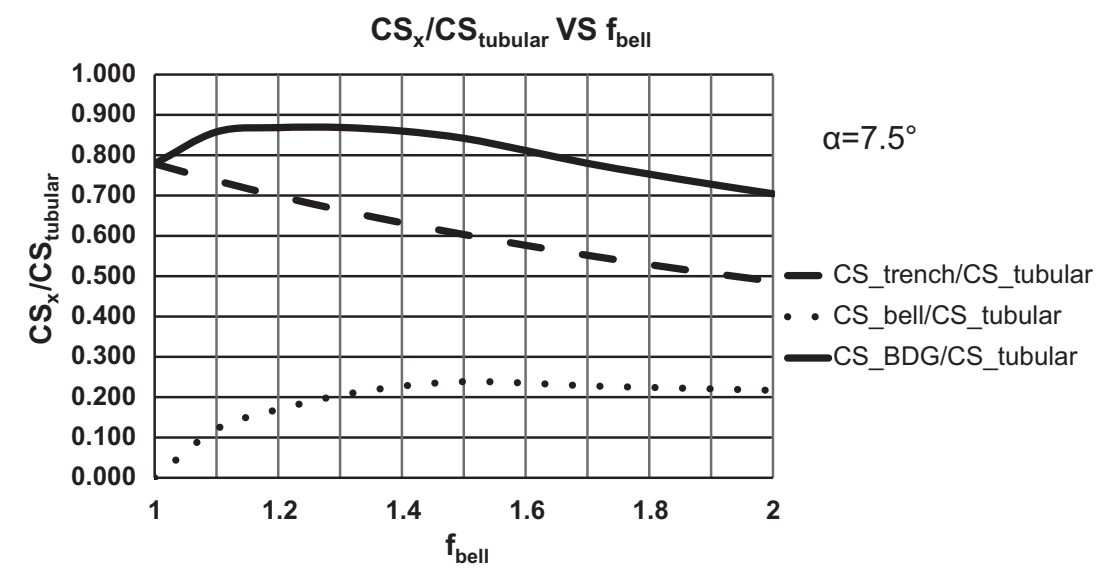

Fig. 4. Variation of $C S_{\text {trench }} / C S_{\text {tubular }}, C S_{\text {bell }} / C S_{\text {tubular }}$ and $C S_{B D G} / C S_{\text {tubular }}$ with $\alpha$ for a fixed $\alpha=7.5^{\circ}$.

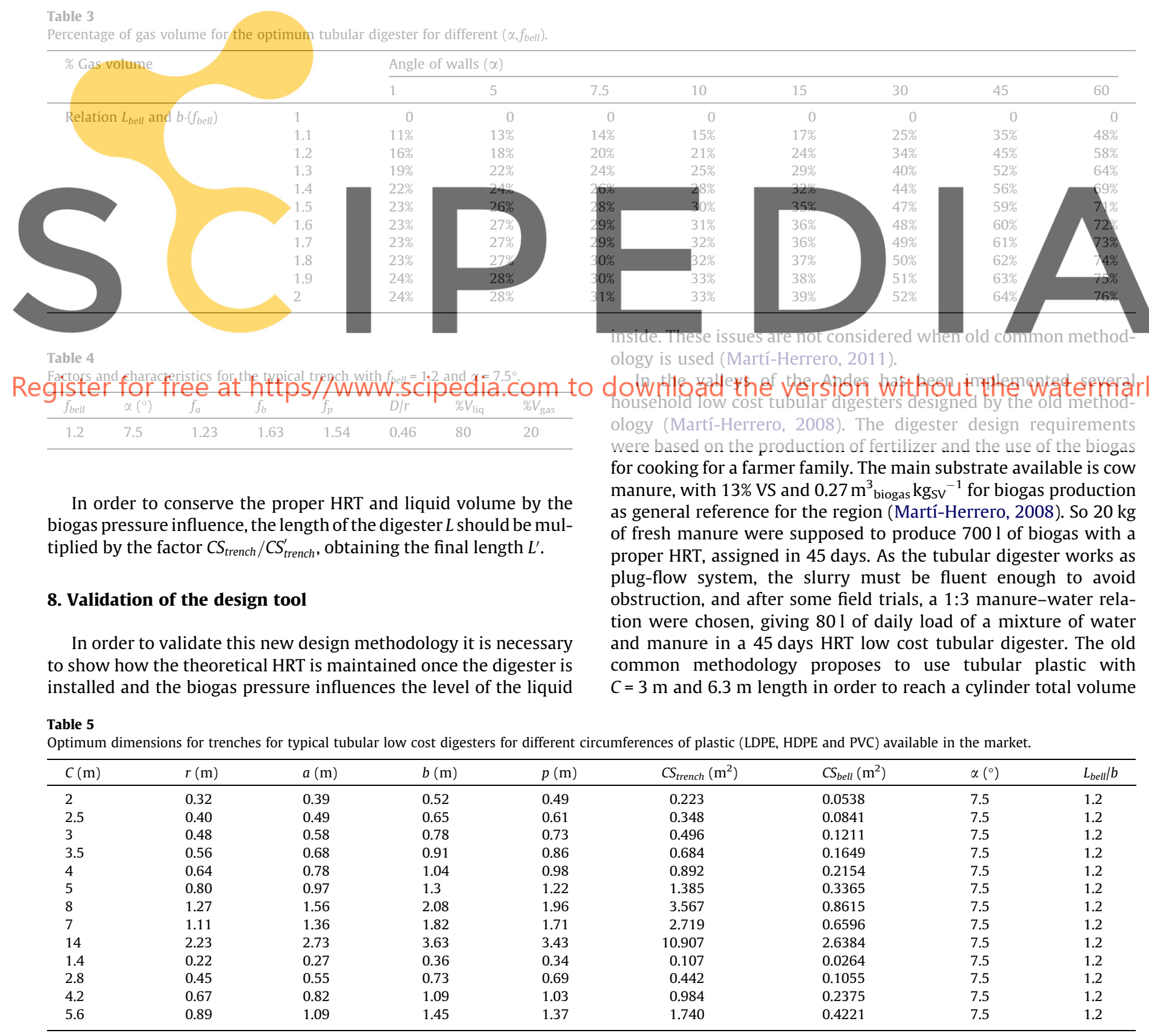


of $4.51 \mathrm{~m}^{3}$. Twenty percent of the total volume will be fulfilled with biogas and $80 \%$ by the liquid. So $3.6 \mathrm{~m}^{3}$ of liquid volume tubular digester is obtained ( 45 day. $0.08 \mathrm{~m}^{3} /$ day $=3.6 \mathrm{~m}^{3}$ ). This methodology could be acceptable if the ditch where the digester would be placed, maintain the tubular shape, but trapezoidal ditches were used. For $C=3 \mathrm{~m}$ the dimensions of the trench proposed in the old methodology are $a=0.5 \mathrm{~m}, b=0.7 \mathrm{~m}$ and $p=0.8 \mathrm{~m}$ (Martí-Herrero, 2011). The resultant liquid volume, once the digester is placed in the trench and loses the tubular shape as it adapts to the trapezoidal trench, is $3 \mathrm{~m}^{3}$, corresponding in this case to 37.5 days of HRT. This is $17 \%$ lower than the HRT considered for design. If the influence of the biogas pressure is considered, the final HRT is 32.3 days, 28\% lower than the desired HRT.

With the methodology proposed in this paper, the same design case, is solved using Table 3 , and selecting $f_{\text {bell }}=1.2$ and $\alpha=7.5^{\circ}$, corresponding to $80 \%$ of liquid volume. So the optimum dimensions of the trench, using the factors of Table 2 and for a $C=3 \mathrm{~m}$, are $a=0.59 \mathrm{~m}, b=0.78 \mathrm{~m}$ and $p=0.74 \mathrm{~m}$. With these dimensions, a $7.1 \mathrm{~m}$ length trench is needed to reach a $3.6 \mathrm{~m}^{3}$ of liquid volume. The next step is to consider the biogas pressure estimating $C S_{\text {trench }} / C S_{\text {trench. }}^{\prime}$. For a typical case of $980.64 \mathrm{~Pa}$ biogas pressure (equivalent to $0.1 \mathrm{~m}$ of water column) $C S_{\text {trench }} / C S_{\text {trench }}^{\prime}=1.18$. So the final length of the digester is $L^{\prime}=7.1 \mathrm{~m} \cdot 1.18=8.37 \mathrm{~m}$ in order to keep the 45 days of HRT once the digester is installed in the trench and in used with a mean biogas pressure of 980.64 Pa.

If the biogas pressure effect is considered with the trench dimensions recommended by the old common methodology

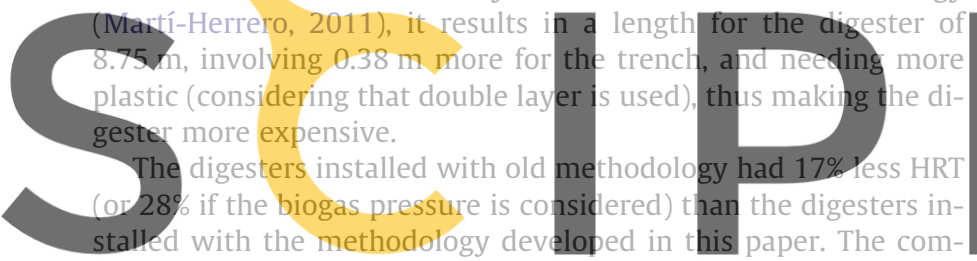
plaints of the new users about biogas production has been reduced, but not removed, perhaps due other social factors as di-

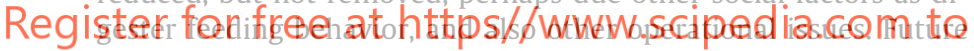
research must be carried out in field research to confirm the improve of the biogas production of the digesters designed with the proposed methodology, that avoid the loss of $17-28 \%$ of HRT.

So, the methodology proposed is validated in order the design low cost tubular digesters with the optimum dimensions (cost effective) in order to keep the designed HRT once the digester is installed and working affected by the biogas pressure.

\section{Conclusions}

The methodology proposed in this paper to obtain the optimum dimensions is based on two determinate parameters: the angle of the walls, and the relation between the length of the arc of the biogas bell, and the upper width of the trench. From these two parameters, and the introduction of the circumference of the plastic that is used to build the tubular digester, one can determine the optimum dimensions of the trench. The influence of the biogas pressure is considered, too.

Finally, the discrepancy showed by different authors in trench dimensions for typical circumferences is solved using this methodology.

\section{Acknowledgements}

This work was carried out with the financial support of the Program EnDev-Bolivia of the GIZ, and with the collaboration of the Research Center of Biodigesters, Biogas and Biol (CIB3, Bolivia) and the Caribbean and Latin American Biodigesters Net (RedBioLAC).

\section{References}

Aguilar, F.X., 2001. How to install a polyethylene biogas plant. United Kingdom: MSc Sustainable Agricultural Systems. The Royal Agricultural College Cirencester. <http://journeytoforever.org/biofuel_library/digeste.pdf> (cited September 2011).

Alvarez, R., Villca, S., Liden, G., 2006. Biogas production from llama and cow manure at high altitude. Biomass Bioenergy 30, 66-75.

Botero, R.B., Preston, T.R., 1987. Biodigestor de bajo costo para la producción de combustible y fertilizante a partir de excretas: Manual para su instalación, operación y utilización. Cali, Colombia: CIPAV; 1987. 20p. <http:// www.utafoundation.org/publications/botero\%26preston.pdf> (cited September 2011)

Bouallagui, H., Ben Cheikh, R., Marouani, L., Hamdi, M., 2003. Mesophilic biogas production from fruit and vegetable waste in a tubular digester. Bioresource Technology 86 (1), 85-89.

Boubaker, Fezzani, Ridha, Ben Cheikh, 2007. Thermophilic anaerobic co-digestion of olive mill wastewater with olive mill solid wastes in a tubular digester. Chemical Engineering Journal 132 (1-3), 195-203.

Bui, X.A., Ngo, M., Duong, N.K., Nguyen, D.A., Preston, T.R., 1995. Installation and performance of low-cost polyethylene tube biodigesters on small-scale farms in Vietnam. National Seminar-workshop "Sustainable Livestock Production On Local Feed Resources”. 1993 Nov 22-27; Ho Chi Minh City. Ho Chi Minh City: Agric. Pub. House, pp. 95-103.

Dinsdale, R.M., Premier, G.C., Hawkes, F.R., Hawkes, D.L., 2000. Two-stage anaerobic co-digestion of waste activated sludge and fruit/vegetable waste using inclined tubular digesters. Bioresource Technology 72 (2), 159-168.

Ferrer, I., Gamiz, M., Almeida, M., Ruiz, A., 2009. Pilot project of biogas production from pig manure and urine mixture at ambient temperature in Ventanilla (Lima, Peru). Waste Management 29, 168-173.

Ferrer, I., Garfí, M., Uggetti, E., Ferrer-Martí, L., Calderon, A., Velo, E., 2011. Biogas production in low-cost household digesters at the Peruvian Andes. Biomass and Bioenergy 35, 1166-1674

Floyd, J.R.S. Hawkes, F.R., 1986, Operation of a laboratory-scale tubular digester on piggery waste. Agricultural Wastes 18, 39-60.

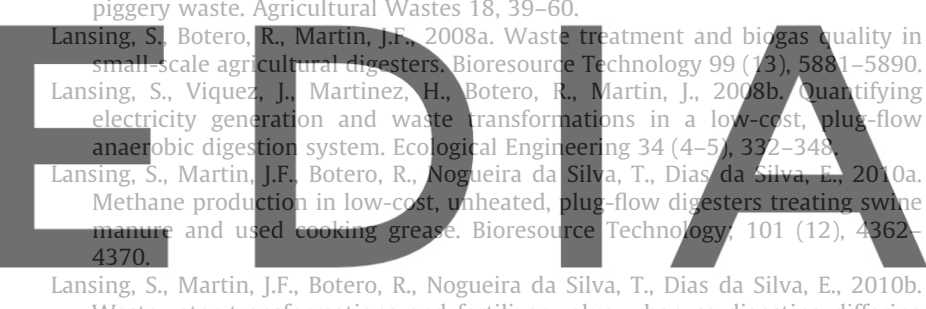
Wastewater transformations and fertilizer value when co-digesting differing

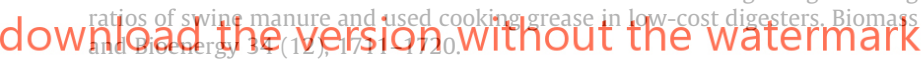
Martí-Herrero, J., 2007. Transfer of low-cost plastic biodigester technology at
household level in Bolivia. Livestock Research for Rural Development 19(12), household level in Bolivia. Livestock Research for Rural Development 19(12),
Article \#192. <http://www.lrrd.org/lird19/12/mart19192.htm> (cited September 2011)

Martí-Herrero, J., 2008. Biodigestores Familiares. Guía de diseño y manual de instalación. La Paz, Bolivia, Cooperación Técnica Alemana-GTZ. ISBN: 97899954-0-339-3. <http://books.google.es/books?id=TsbrdcmKGKoC> (cited September 2011).

Martí-Herrero, J., 2011. Reduced hydraulic retention times in low-cost tubular digesters: two issues. Biomass and Bioenergy 35 (10), 4481-4484.

Ong, H.K., Greenfield, P.F., Pullammanappallil, P.C., 2000. An operational strategy for improved biomethanation of cattle-manure slurry in an unmixed, single-stage, digester. Bioresource Technology (73), 87-89.

Poggio, D., Ferrer, I., Batet, Ll. y Velo E., 2009. Adaptación de biodigestores tubulares de plástico a climas fríos. Livestock Research for Rural Development 21(9), Article \#152. <http://www.lrrd.org/lrrd21/9/pogg21152.htm> (cited September 2011).

Pound, B., Bordas, F., Preston, T.R., 1981. Characteristics of production and function of a 15 cubic metre Red-Mud PVC biogas digester. Tropical Animal Production 6, 146-153, <http://www.utafoundation.org/UTAINFO1/TAP/TAP62/62_146.pdf> (cited September 2011).

Rodriguez, L., Preston, T.R., 1999. Biodigester installation manual. University of Tropical Agriculture Foundation, University of Agriculture and Forestry Thu Duc, Ho Chi Minh City, Vietnam. <http://www.fao.org/ag/aga/agap/frg/Recycle/ biodig/manual.htm> (cited September 2011).

Sarwatt, S.V., Lekule, F.P., Preston, T.R., 1995. On-Farm Work with Low Cost Tubular Plastic Biodigesters for Resource-poor Farmers in Tanzania. In: Dolberg, F., Petersen, P.H. (Eds.). "Agricultural science for biodiversity and sustainability in developing countries: proceedings of a workshop. 1995 April 3-7; Tune Landboskole, Denmark, pp. 199-205.

Soeurn, T., 1994. Low cost biodigesters in Cambodia. In: Preston, T.R., Ly, L.V., Hieu, L.T., Ogle, B. (Eds.), Proceedings of National Seminar-workshop "Sustainable Livestock Production on Local Feed Resources”, 1993 Nov 22-27; Ho Chi Minh City: Agric. Pub. House, pp. 81-90.

Solarte, A., 1995. Sustainable livestock systems based on local resources: CIPAVs experiences. 2nd Intl. Conference on Increasing Animal Production with Local Resources. Zhanjiang, China. Electronic Proc, p. 2. 